\title{
Toxicity of TiO2, SiO2, ZnO, CuO, Au and Ag engineered nanoparticles on hatching and early nauplii of Artemia sp.
}

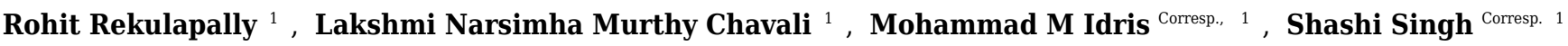 \\ ${ }^{1}$ Centre for Cellular and Molecular Biology, Hyderabad, Telangana, India \\ Corresponding Authors: Mohammad M Idris, Shashi Singh \\ Email address: idris@ccmb.res.in, shashis@ccmb.res.in
}

The potential of environmental release enhances with increased commercial applications of the nanomaterials. In this work, a simple and efficient test to estimate the acute toxicity of nanoparticles is carried out on Artemia species and their hatching rates. We have tested six different engineered nanoparticles (silver, gold, cop per oxide, zinc oxide, $\mathrm{TiO}_{2}$ and $\mathrm{SiO}_{2}$ dioxide nanoparticles) and three soluble salts $\left(\mathrm{CuSO}_{4}, \mathrm{ZnSO}_{4}\right.$ and $\mathrm{AgNO}_{3}$ ) on Artemia sp. The physiochemical properties of the nanoparticles involved in this study are estimated and their properties in normal water and marine water were analyzed. Hydrated and bleached Artemia cysts were allowed to hatch in continuously aerated, filtered sterile salt water containing nanoparticles; hatching of viable nauplii and total hatchlings have been recorded. In parallel, Standard Artemia toxicity test was conducted on the nauplii monitoring the viability. In hatching experiments, a reduction in hatching rate was observed along with mortality of newly hatched nauplii. The results of the hatching experiment and of the standard Artemia test showed a good correlation. The toxicity of the nanoparticles was compared and the order of toxicity was estimated as $\mathrm{Ag}>\mathrm{CuO}>\mathrm{ZnO}>\mathrm{Au}>\mathrm{TiO}_{2}>\mathrm{SiO}_{2}$. The study thus suggests that the hatching test itself is a reliable assay for determining the toxicity of nanomaterials. 
$31 *$ These authors contributed equally to this work.

\section{Toxicity of $\mathrm{TiO}_{2}, \mathrm{SiO}_{2}, \mathrm{ZnO}, \mathrm{CuO}, \mathrm{Au}$ and $\mathrm{Ag}$ engineered nanoparticles on hatching and early nauplii of Artemia sp.}


32 rohit_r@ccmb.res.in; chlnmurthy@ccmb.res.in

33

34

35

36

37

\section{Abstract}

The potential of environmental release enhances with increased commercial applications of the nanomaterials. In this work, a simple and efficient test to estimate the acute toxicity of nanoparticles is carried out on Artemia species and their hatching rates. We have tested six different engineered nanoparticles (silver, gold, copper oxide, zinc oxide, $\mathrm{TiO}_{2}$ and $\mathrm{SiO}_{2}$ dioxide nanoparticles) and three soluble salts $\left(\mathrm{CuSO}_{4}, \mathrm{ZnSO}_{4}\right.$ and $\left.\mathrm{AgNO}_{3}\right)$ on Artemia sp. The physiochemical properties of the nanoparticles involved in this study are estimated and their properties in normal water and marine water were analyzed. Hydrated and bleached Artemia cysts were allowed to hatch in continuously aerated, filtered sterile salt water containing nanoparticles; hatching of viable nauplii and total hatchlings have been recorded. In parallel, Standard Artemia toxicity test was conducted on the nauplii monitoring the viability. In hatching experiments, a reduction in hatching rate was observed along with mortality of newly hatched nauplii. The results of the hatching experiment and of the standard Artemia test showed a good correlation. The toxicity of the nanoparticles was compared and the order of toxicity was estimated as $\mathrm{Ag}>\mathrm{CuO}>\mathrm{ZnO}>\mathrm{Au}>\mathrm{TiO}_{2}>\mathrm{SiO}_{2}$. The study thus suggests that the hatching test itself is a reliable assay for determining the toxicity of nanomaterials. 
54

55

56

57

58

59

60

61

62

\section{Introduction}

Nanomaterials with their ever expanding diversity, unique properties, and endless applications pose risk to environment and human health. There is a dearth of information on the impact or the risk of nanoscale objects to the environment. Increasing utility would mean enhanced exposure of the ecosystems to these unknown risks. Their release into environment may start with production, during their applications, by weathering and finally wastes.

Nanomaterials can be designed from almost any material -metal/oxides, carbon, organic, biomaterial, etc and in any form, by strictly adhering to the size range of nanometer at least in one dimension. Nanomaterials behave differently from the bulk due to their unique physicochemical properties. Information on predictability of their behaviour or state in due course is almost negligible. Not only there is limited information on the bioavailability and biopersistence of these particles, the behaviour of the particles in various conditions like $\mathrm{pH}$, salinity and other biotic factors is not clearly known $[1,2]$. Efforts are currently on to identify the risks associated with the nanomaterial applications.

Hazard identification is an important step for risk assessment of nanomaterials. Most of the methodologies used in hazard identification are the ones used for chemicals in general. Being different from bulk material, the nanoforms of the same materials may pose some restraints or advantages in the use of methodologies.

Aquatic systems are the inevitable receptacles for the materials released in the environment. The organisms therein get exposed to the nanomaterials accumulated from seepage and flow through. Many assays for ecotoxicology have been tested for nanomaterials - using bacteria [3], fishes and fish embryos [4, 5]; copepods [6]; Daphnia [7,8]. In this study Artemia sp. are used to study the nanomaterial toxicity. Artemia is a non-selective filter feeder organism which is available worldwide in highly saline waters. Due to their ubiquitous distribution, robust nature and cost effective culturing conditions they make a good model organism for toxicological assays. Though Artemia are considered to be one of the insensitive models for a lot of chemicals, the early developmental stages of Artemia are highly vulnerable to many of the test materials. Few 
84 studies are reported for nanomaterial toxicity using Artemia sp. also [9-13]. Selection of end 85 point is a factor worth considering while evaluating sensitivity of the species. Most of the studies

86

102

103

104

105

106

107

108

109

110

111

112

113 are carried out in newly hatched nauplii that are exposed to varying concentration of nanomaterial; Hatching of hydrated cysts has not been used as an end point for toxicity except in [14-17] though some earlier studies had shown sensitivity of hatching rate of Artemia to metals [18-20].

In this study, the nanomaterial we have evaluated are metals and metal oxide nanoparticles (NP); these have a high production globally due to their demand for diverse applications applicability. Generally, these nanomaterials find widespread applications as their corresponding bulk materials are non toxic.

Acute toxicity of 4 metal oxide nanoparticles $\left(\mathrm{TiO}_{2}, \mathrm{SiO}_{2}, \mathrm{ZnO}\right.$ and $\left.\mathrm{CuO}\right)$ and two metal nanoparticles ( $\mathrm{Ag}$ and $\mathrm{Au}$ ) to nauplii of Artemia and on the hatching of their hydrated cysts has been studied. For the standard Artemia test and hatching test, mortality and hatching rates were considered as end points. Both the tests exhibit a good inverse correlation in sensitivity to nanoparticles, thereby implying that a bioassay based on hatching can be developed for hazard assessment of nanoparticles.

\section{Materials and Methods}

\section{Preparation of nanoparticles and their characterization}

All the nanoparticles used in the study were obtained from the consortium NANOVALID project. $\mathrm{SiO}_{2}$ nanoparticles (powder form) were supplied by Nanologica $\mathrm{AB}$, Silver nanoparticles were obtained as a suspension of $4 \%$ from Colorobbia; Gold nanoparticles as a suspension of $0.006 \%$ from INMETRO., Copper oxide nanoparticles (powder form) from Intrinsiq Materials (UK)., Zinc oxide nanoparticles (powder form) from Nanogate (Germany) and $\mathrm{TiO}_{2}$ particles were synthesized in house using the existing protocol [21]. The nanoparticles obtained in powder form were made into a suspension. A suspension of NPs was made by suspending $\mathrm{SiO}_{2}, \mathrm{TiO}_{2}, \mathrm{CuO}$ and $\mathrm{ZnO}$ NPs at a concentration of $2 \mathrm{mg} / \mathrm{ml}$. The suspension was sonicated at $\sim 30 \mathrm{~W}$ with pulse of $50 \%$ for 10 minutes. Silver nanoparticles were obtained as suspension at a concentration of 4\% with PVP (polyvinylpyrrolidone) as a stabilizing agent, gold 
114 nanoparticles in water at a concentration of $0.006 \%$. Working dilutions of the nanoparticles were

115 prepared in salt water (Oceanfish marine salt; Prodac International) for the experiments.

116

117 The nanoparticles used in this study were characterized in the NANOVALID consortium in 118 round robin manner. TEM (transmission electron microscopy) and DLS (dynamic light 119 scattering) were used in this study for basic characterization of nanoparticles before every 120 experiment. In TEM studies the nanoparticle suspension of $50 \mu \mathrm{g} / \mathrm{ml}$ was applied to formvar 121 coated copper grids and air dried. The grids were examined in JEOL 2010 TEM at 100KV using $12220 \mu$ aperture, about 10 images were taken using GATAN camera and later analysed using 123 GATAN software. The Images of about 100 particles were used for analysis. The nanoparticle 124 suspensions at concentration of $25 \mu \mathrm{g} / \mathrm{ml}$ in milliQ water and salt water were measured in 125 Dynamic light scattering system (Horiba Nanopartica SZ100). Each suspension was analyzed 126 thrice up to 48 hours and the data was represented as mean \pm SEM. Solvents used to prepare the nanoparticles were used as controls for size determination.

\section{Hatching of Artemia}

130 For every 1 litre culture, 1.0 gram of Artemia cysts were used (San Francisco Bay strain). These cysts were hydrated in distilled water under aeration for 45 minutes and then bleached to decapsulate the cysts wall using 20\% sodium hypochlorite solution for 15 minutes. The bleached Artemia eggs were then washed for 6 times with distilled water and allowed to hatch in $2.5 \%$ salt water $(\mathrm{pH} 8.0)$ with continuous light and aeration for 24 hours [22]. The temperature was maintained at $28^{\circ} \mathrm{C}$, the optimum temperature for hatching of Artemia cysts. Nanoparticles were added to the culture in concentrations of $100 \mathrm{mg} / \mathrm{L}$ and $10 \mathrm{mg} / \mathrm{L} . \mathrm{pH}$ of the salt water containing nanoparticles was always determined using $\mathrm{pH}$ meter after setting the $\mathrm{pH}$ meters with two reference standards at $\mathrm{pH} 7$ and 9.

\section{Toxicity studies using hatching rate as end point}

141 Six types of nanoparticles $\left(\mathrm{TiO}_{2}, \mathrm{SiO}_{2}, \mathrm{ZnO}, \mathrm{CuO}, \mathrm{Au}\right.$ and $\left.\mathrm{Ag}\right)$ are tested for their toxicity on 142 brine shrimp hatching. The Artemia cysts were allowed to hatch under standard culture 143 conditions and in presence of two different concentrations of each nanomaterial $(100 \mathrm{mg} / \mathrm{L} \mathrm{\&}$ $14410 \mathrm{mg} / \mathrm{L})$. The hatching rate, mortality and viability were checked after 24 hours for each Artemia 
145 cultures exposed to nanoparticle. Three aliquots of $100 \mu 1$ was taken from each flask after 146 thorough mixing and counted under the stereo-microscope. Both, hatched Artemia (immotile vs. 147 motile) $[\mathrm{h}]$, and unhatched $[\mathrm{u}]$ cysts were counted. Hatching rate was expressed as percent of 148 total number of fully hatched Artemia [H] in comparison to total Artemia in the aliquot. The experiment was repeated six times. The average and SEM was calculated for each sample.

150

151

Hatching rate $=\mathrm{h} / \mathrm{H} \times 100$

152

153

154

\section{Standard Artemia toxicity Test}

In a second set of experiments, following the protocol of Solis [23], Artemia hatched under

normal conditions in salt water were exposed to various nanoparticles. 10 nauplii were

transferred to six well plates and the nanoparticles at $100 \mathrm{mg} / \mathrm{L}, 10 \mathrm{mg} / \mathrm{L}, 1 \mathrm{mg} / \mathrm{L}, 0.1 \mathrm{mg} / \mathrm{L}$ and $0.01 \mathrm{mg} / \mathrm{L}$ concentrations were added. The number of live larvae was counted at intervals of 6 , 12, 18, 24, 36 and 48 hours. Mortality of the larvae was used as end point. Mortality was recorded as cessation of swimming or any movement by nauplii. $\mathrm{LC}_{50}$ was calculated for each particles using Graphpad software (www.graphpad.com/quickcalcs/).

\section{Oxidative stress test}

Stresses due to reactive oxidation species can be observed by treating the nauplii exposed to different concentrations with $10 \mu \mathrm{M}$ DCFDA (dichloro-flourescien diacetate). DCFDA or with $20 \mu \mathrm{M}$ Dihydroethidium(DHE), both of which are chemiluminiscent probes and react with ROS generated due to oxidative stress. The nanoparticle treated nauplii exposed to DCFDA or DHE are imaged in Zeiss Axiovert imager using appropriate filters.

\section{Validity of results}

171 The hatching studies have been conducted 6 times and the validity criterion used is, low mortality in the control. The data was analyzed for statistic validation using Graphpad software

173 (www.graphpad.com/quickcalcs/). In the Artemia toxicity tests the validity criterion was 174 mortality below $10 \%$ in $24 \mathrm{hr}$ period. The correlation test was performed for both sets of data 175 using on line software for correlation coefficient and comparing data using Microsoft excel. 


\section{Results}

182

\section{Analysis of nanoparticles}

184

The size of nanoparticles both in distilled water and salt water was measured. The nanoparticles showed reduced size in salt water by Transmission Electron Microscopy. The transmission electron microscope studies showed no apparent change in aggregation or dispersion of particles (Figure 1). Measurement of particle size by DLS which allows examination of particles sizes as well as aggregates when in suspension revealed that nanoparticles exhibited different aggregation profiles in milliQ (mQW) water and salt water $(\mathrm{SW}) . \mathrm{TiO}_{2}(7082 \mathrm{~nm}$ in $\mathrm{mQW}: 8009$ $\mathrm{nm}$ in $\mathrm{SW}), \mathrm{CuO}$ (329nm in mQW: $468 \mathrm{~nm}$ in SW) and $\mathrm{ZnO}(117 \mathrm{~nm}$ in mQW: $185 \mathrm{~nm}$ in $\mathrm{SW}$ ) nanoparticles showed higher values for aggregate sizes in salt water as shown in Figure 2. Silver (169nm in mQW: $101 \mathrm{~nm}$ in SW), Gold (5542 nm in DW: $3712 \mathrm{~nm}$ in SW) and $\mathrm{SiO}_{2}(7704 \mathrm{~nm}$ in DW: $6096 \mathrm{~nm}$ in SW) had smaller aggregates in salt water as compared to particles in MilliQ water (Figure 2). Visible flocculation was observed in case of Copper and Zinc oxide nanoparticles. DLS measurements for these nanoparticles gave very high values corroborating the flocculence seen (Figure 2). Though size changes in the mean size of particles in milliQ and salt water was noticed both by TEM and DLS, it was not found to be significant in statistical analysis (Table 1).

The nanoparticles suspended both in MilliQ water and $2.5 \% \mathrm{NaCl}$ solution (salt water) were 201 measured up to 48 hours to observe change, if any in their dispersion pattern (Figure S1). Silver NPs, $\mathrm{TiO}_{2}$ and $\mathrm{SiO}_{2}$ did not show much difference in dispersion in MilliQ water over 48 hours but the particles showed higher aggregate sizes in salt water in 48 hours. In $\mathrm{CuO}$ and $\mathrm{ZnO}$ NPs visible flocculation and sedimentation was seen in case of both MilliQ and salt solution by 48 205 hours. 


\section{Hatching studies}

208 Brine shrimp Artemia were allowed to hatch in filtered sterile salt water kept at continuous

209

210

211

212

213

214

215

216

217

218

219

220

221

222

223

224

225

226

227

228

229

230

231

232

233

234

235

236 aeration that also keeps the particles in suspension throughout the experiment. Brine shrimp showed a hatching rate of $74 \% \pm 5.5$ in milliQ water and the viability of these hatched nauplii was about $97 \%$. The hatching rate of Artemia altered drastically in presence of nanoparticles (Table 2; Figure 3). The hatching rate dropped with increase in concentration of nanoparticles in salt water. The highest effect was seen in presence of silver and copper oxide nanoparticles. The hatching rate dropped to about $29 \%$ in presence of these two nanoparticles at a concentration of $100 \mathrm{mg} / \mathrm{L}$; of these only $50 \%$ were motile and viable at a concentration of $100 \mathrm{mg} / \mathrm{L}$ (Table 2). The hatching rate remained lower at $10 \mathrm{mg} / \mathrm{L}$ of silver nanoparticles but the viability of hatched nauplii was good at $85 \%$. With copper oxide also hatching rate was low (43.23\%) with better viability around $64 \%$. Similarly, with silver nitrate or in presence of capping agent PVP the hatching slightly improved (33\% and $41 \%$ respectively) with good viability of 70 and $84 \%$, and about $60 \%$ in case of copper sulphate with viability of $33 \%$.

Hatching rate in presence of other nanoparticles (gold, $\mathrm{SiO}_{2}, \mathrm{TiO}_{2}$, copper oxide and zinc oxide) was low at about 50-60\% as compared to control (Table 2; Figure 3) and post-hatching mortality was not very high. In presence of zinc oxide nanoparticles, $60 \%$ of the nauplii hatched but the cysts had a tendency to clump together. $\mathrm{In} \mathrm{TiO}_{2}$ at $100 \mathrm{mg} / \mathrm{L}$, hatching rate was $41.50 \%$ with 67.8 $\%$ viability; the hatching rate was at $54 \%$ with $\sim 90 \%$ viability in $10 \mathrm{mg} / \mathrm{L} \mathrm{TiO}_{2}$ dioxide $\mathrm{NPs}$. Gold and $\mathrm{SiO}_{2}$ nanoparticles displayed very good viability after hatching (Figure 3). $\mathrm{SiO}_{2}$ nanoparticles at a concentration of $10 \mathrm{mg} / \mathrm{L}$ displayed hatching rate and viability equivalent to the controls.

The $\mathrm{pH}$ of salt water did not change upon addition of nanoparticles and remained around 8.3-8.5 up to 48 hours. Live hatched nauplii appeared normal and swimming vigorously. There were no visible changes in morphology of nauplii hatched in presence of nanoparticles. Some of the nauplii had emerged but were immotile/dead; some were trapped in the membrane and still-dead (Figures S2.1-2.6). Silver and copper oxide nanoparticles which had maximum toxic effect on hatching rate also did not show any gross morphological abnormalities. Staining of hatched 
237 Artemia with DCFDA revealed oxidative stress in a few still trapped nauplii and the gut of dead 238 nauplii (Figure S3).

239

\section{Larval toxicity test}

241 Following the ARC (Artemia Reference Centre) test protocol, the larvae hatched in salt water were exposed to nanoparticles for up to 48 hours and the viability recorded every 6 hours for first 24hours and subsequently every $12 \mathrm{hrs}$. Artemia were not fed during the test period. The nauplii showed variability in mortality to various nanoparticles. The most toxic was the silver nanoparticles and silver in ionic form (Table 3). Silver in ionic form was highly toxic as $80 \%$ of the nauplii were dead in 24 hours in silver nitrate solution (Figure 4). The $\mathrm{LC}_{50}$ of the silver nanoparticles was around $10.12 \mathrm{mg} / \mathrm{L}$ at 24 hours. Other nanoparticles used in the study were nontoxic initially but after 30 hours (Table 3), Many Artemia died in concentration dependent manner (Figure 4). $\mathrm{LC}_{50}$ of gold was $7.54 \mathrm{mg} / \mathrm{L}$ at $48 \mathrm{~h} . \mathrm{LC}_{50}$ of $\mathrm{SiO}_{2}, \mathrm{TiO}_{2}$ and $\mathrm{CuO}$ was 23.59; 18.94 and $20.92 \mathrm{mg} / \mathrm{L}$ at 48 hours. In presence of zinc oxide nanoparticles, around 36\% nauplii perished in $48 \mathrm{hrs}$ in the highest concentration used with the $\mathrm{LC}_{50}$ above $100 \mathrm{mg} / \mathrm{L}$ at around $259.34 \mathrm{mg} / \mathrm{L}$. Ionic forms of silver, copper and zinc were found to be more toxic than their corresponding nanoforms having $\mathrm{LC}_{50} \mathrm{Ag}^{+}(8.19 \mathrm{mg} / \mathrm{L}), \mathrm{Cu}^{++}(13.5 \mathrm{mg} / \mathrm{L})$ and $\mathrm{Zn}^{++}(0.769 \mathrm{mg} / \mathrm{L})$.

In the ARC test; we do see sedimentation and flocculation of nanoparticles by $48 \mathrm{hrs}$. The nauplii maintained in salt water containing nanoparticles showed accumulation of NPs in the gut of Artemia by end of 24 hours (Figure 5). In case of silver nanoparticles, the nauplii that were dead within 24 hours, the gut does not show accumulation of material (Figure 5), even the nauplii appeared stunted. Staining of the nauplii exposed to nanoparticles showed signs of stress when stained with DCFDA for ROS and DHE for Superoxide (Figure 5). Nauplii exposed to silver nanoparticles showed highest staining, followed by $\mathrm{TiO}_{2}$ and $\mathrm{SiO}_{2}$. Nauplii exposed to other nanoparticles do not show any signs of stress did show accumulation of nanoparticles in the gut (Figure 5).

\section{Discussion}

266 In this study, we have compared hatching rate of Artemia cyst in presence of nanoparticles and 267 the toxicity of nauplii using standard Artemia test at various concentrations of nanoparticle 
268 suspension in high salinity conditions. We found a strong correlation in hatching rates and larval 269 mortality in various nanoparticle suspensions (Figure 6).

270

271 Artemia are able to tolerate high salinity and adapt to extreme conditions. They have wide

272 distribution globally and the collection of cysts is easily. Artemia cysts are dormant gastrula 273 states during development encased in hard outer shell; formed under unfavourable conditions.

274 Under simple laboratory conditions, the cysts can be hatched in high salinity water when by 275 about 20 hours the umbrella stage emerges and yields free swimming nauplii [24, 25]. In the 276 hatching test, we counted the number of umbrella stage and nauplii after 24 hours, among the 277 hatched larvae, number of motile nauplii were recorded for each tested nanoparticle. Hatching or 278 emergence of the nauplii has been reported earlier as a sensitive bioassay to study the molecular 279 and physiological effects of metals $[15,26]$. Lower hatching rate equates with the toxicity of test 280 compound. Hatching has been used as an end point by some more laboratories while studying 281 toxicity (15-17). Hatching of cysts can vary depending on a number of factors like geographical 282 origin of cysts, salinity of hatching media, temperature, luminosity, $\mathrm{pH}$ etc. (27) Despite all the 283 factors, reduction in emerging nauplii during hatching has proven to be a reliable an end point 284 for toxicity studies.

285 Keeping the salinity at $2.5 \%, \mathrm{pH}$ above 8 , and temperature constant in all experimental 286 conditions, we show that hatching rates are affected in presence of nanoparticles of metals and 287 metal oxides. Silver and copper oxide nanoparticles show high toxicity among the various 288 particles tested in concentration dependent manner. To rule out the toxicity due to released ions 289 from the nanoparticles, the nanoparticle suspension was centrifuged and resuspended in brine 290 solution (28). These resuspended particles were seen as nanoparticles even after 72 hours in high 291 salinity water and cause toxicity by affecting both hatching rates and viability. Though ionic 292 silver precipitated out due to salt in water, it continued to affect the hatching and subsequent 293 viability of the nauplii. Solutions of silver nitrate copper sulfate and zinc sulfate representing 294 ionic forms also showed high toxicity. Hatching of cysts can be affected by lower $\mathrm{pH}$ (27) but our studies showed that the $\mathrm{pH}$ of salt water containing nanoparticles also remained above 8 . Other nanoparticles like; gold, $\mathrm{TiO}_{2}$ and $\mathrm{SiO}_{2}$ nanoparticles had some effect on hatching rates and survival after hatching in concentration dependent manner. $\mathrm{SiO}_{2}$ nanoparticles at low concentration were very conducive to and in fact showed better hatching as compared to control 
299 (Supplementary table 1). Hatching rates in presence of nanoparticles were not much different at 30020 hours and 24 hours but the mortality of hatched nauplii was higher in some nanoparticles at 30124 hours (data not shown). Locomotion of the hatched nauplii was also affected in presence of 302 nanoparticles.

303

In the standard Artemia test, nauplii hatched in salt water are exposed to nanoparticle 305 suspensions. The mortality and toxic effects expressed as $\mathrm{LC}_{50}$; the concentration of an agent at 306 which 50 per cent of the tested animals are dead after $24 \mathrm{hr}$; were chosen as criteria of the 307 toxicity [29]. The standard Artemia toxicity test results were comparable and silver nanoparticles ranked very high in toxicity, followed by copper and zinc oxide nanoparticles. $\mathrm{TiO}_{2}$, gold and $\mathrm{SiO}_{2}$ nanoparticles in that order, showed a better survival of nauplii up to $48 \mathrm{hrs}$. On comparing the two methods, a good inverse correlation was observed between the results obtained i.e. effects of NPs on hatching rates and effect on mortality of the hatched larvae $(r=-0.79)$. The particles that reduced the hatching rate showed an increase in mortality in the ARC test using the normally hatched nauplii. Our results correlate well with some previous reports, where toxicity assays were performed on Artemia using nanoparticles [30, 31, 11]. Comparing the viability of nauplii (inverse of mortality) in ARC test with the hatching rate showed no statistically significant difference in the mean values for each concentration of different particles $(\mathrm{P}=0.683)$ in the paired $\mathrm{T}$ test.

The advantage of the hatching assay is that it is easy to perform, short term and uses mortality as the end point for assessing toxicity of the test material. The question of altered solubility may not arise though sedimentation of these suspensions sometimes may vary for different particles. So

322 far we have seen that nanoparticles tested in this work remain stable in seawater up to one week, 323 though the ionic or dissolved component may settle down due to precipitation. The sedimentation factor is taken care of by the continuous aeration in the hatching test that keeps the particles in suspended form.

Organisms in aquatic environment like daphnia incorporate NPs via gut. Artemia is also a filter feeder and the NPs may enter the guts of Artemia through ingestion. The mortality observed may 329 be due to the uptake of the NPs clogging the gut as most of the nauplii in presence of NPs show 
330 presence of particles in the digestive tract. In the hatching test, the dead Artemia and partially

331 hatched cysts show increased oxidative stress in presence of nanoparticles as indicated by

332 DCDFA staining. Even the nauplii exposed to some nanoparticles like silver NPs showed

333 accumulation of ROS and superoxide but with remaining nanoparticles it is likely that the gut

334 accumulation of the NPs is the cause of mortality.

335

336

Artemia with capacity to homeostasis in variable external salt concentrations certainly appears to be a model organism to assess the nanoparticle behaviour and ecotoxicity. Suitability of Artemia

for toxicity tests is established and is often used in pharmaceutical industry and for metal and radiation toxicity [32-34]. We propose that Artemia hatchability test along with standard lethality/toxicity test definitely could also be used as pre-screening of nanoparticle toxicity prior to their validation through in vivo toxicity studies. These acute toxicity tests eliminate the need of laboratory maintenance of test species which otherwise take up space and time. Use of cysts which are available in enormous quantities as batch also cut down on the variability in test 344 species.

\section{Conclusions}

Hatchability of Artemia can be used as a quick screening test for toxicity of materials without much need for laboratory space and maintenance. With strictly laid out protocols and test conditions, this assay can be adopted for the hazard identification of nanomaterials and high through put methods.

\section{References}

1. Musee, N. Nanowaste and the environment: Potential new waste management paradigm. Environment International 37, 112-128 (2011).

2. Moore, M.N. Do nanoparticles present toxicological risks for the health of the aquatic environment? Environment International, 32, 967-976 (2006). 
360

361

362

363

364

365

366

367

368

369

370

371

372

373

374

375

376

377

378

379

380

381

382

383

384

385

386

387

388

389

3. Suppi, S., Kasemets, K., Ivask, A., Künnis-Beres, K., Sihtmäe, M., Kurvet, I., Aruoja, V., \& Kahru, A novel method for comparison of biocidal properties of nanomaterials to bacteria, yeasts and algae. J Hazard Mater. 286, $75-84$ (2015).

4. Rizzo, L.Y., Golombek, S. K., Mertens, M.E., Pan, Yu, Laaf, D., Broda, Jayapaul, J., Möckel, D., Subr, V., Hennink, W. E., Storm, G.,Simon, U., Jahnen-Dechent, W., Kiesslinga, F \& Lammers T.In Vivo Nanotoxicity Testing using the Zebrafish Embryo Assay. J Mater Chem B Mater Biol Med1, doi:10.1039/C3TB20528B (2013).

5. Zhu, X., Zhu, L., Duan, Z., Qi, R., Li, Y. \& Lang, Y. Comparative toxicity of several metal oxide nano-particle aqueous suspensions to Zebrafish (Danio rerio) early developmental stage. J Environ Sci Health ATox Hazard Subst Environ Eng. 43, 278-84 (2008).

6. Templeton, R. C., Ferguson, P. L., Washburn, K. M., Scrivens, W. A. \& Chandler, G. T. Life-cycle effects of single-walled carbon nanotubes (SWNTs) on an estuarine meiobenthic copepod. Environmental Science \& Technology. 40, 7387-93 (2006).

7. Adam, N., Schmitt, C., Galceran, J., Companys, E., Vakurov, A., Wallace, R., D Knapen \& Blust $\mathrm{R}$ The chronic toxicity of $\mathrm{ZnO}$ nanoparticles and $\mathrm{ZnCl}_{2}$ to Daphnia magna and the use of different methods to assess nanoparticle aggregation and dissolution.Nanotoxicology 8, 709-717 (2014).

8. Völker, C., Boedicker, C., Daubenthaler, J., Oetken, M. \&Oehlmann, J. Comparative Toxicity Assessment of Nanosilver on Three Daphnia Species in Acute, Chronic and Multi-Generation Experiments. PLoS ONE8, e75026 (2013).

9. Arulvasu, C., Jennifer, S. M., Prabhu, D. \& Chandhirasekar, D. Toxicity Effect of Silver Nanoparticles in Brine Shrimp Artemia. The Scientific World Journal ID 256919, http://dx.doi.org/10.1155/2014/256919 (2014).

10. Ates, M., Daniels, J., Arslan, Z. \& Farah, I. O. Effects of aqueous suspensions titanium dioxide nanoparticles on Artemia salina: assessment of nanoparticle aggregation, accumulation and toxicity. Environmental Monitoring and Assessment 185, 3339-3348 (2012).

11. Ates, M., Daniels, J., Arslan, Z., Farah, I. O. \&Rivera, H. F. Comparative evaluation of impact of $\mathrm{Zn}$ and $\mathrm{ZnO}$ nanoparticles on brine shrimp (Artemia salina) larvae: effects of 
390

391

392

393

394

395

396

397

398

399

400

401

402

403

404

405

406

407

408

409

410

411

412

413

414

415

416

417

418

particle size and solubility on toxicity. Environ Sci Process Impacts1; (1), doi:10.1039/c2em30540b (2013).

12. Ates, M., Demir, V., Arslan, Z., Daniels, J., Farah, I. O. \& Bogatu, C. Evaluation of Alpha and Gamma Aluminum Oxide Nanoparticle Accumulation, Toxicity, and Depuration in Artemia salina Larvae. Environ Toxicol 30, 109-118 (2015).

13. Rajabi, S., Ramazani, A., Hamidi, M. \& Naji, T. Artemia salina as a model organism in toxicity assessment of nanoparticles. DARU Journal of Pharmaceutical Sciences 23, 20 (2015).

14. Carballo, J. L., Herna'ndez-Inda Z. L., Pe'rez P. \& Garc1'a-Gra'valos M. D. A comparison between two brine shrimp assays to detect in vitro cytotoxicity in marine natural products. BMC Biotechnology 2, 17 (2002).

15. Migliore L, Civitareale C, Brambilla G, \& di Delupis GD Toxicity of several important agricultural antibiotics to Artemia. Water Res 31,1801-1806 (1997)

16. Rotini, A, Manfra L, Canepa S, Tornambe, A, \& Migliore L. Can Artemia Hatching assay can be a (Sensitive) Alternative tool to acute toxicity test? Bull Environ.Contam Toxicol 95,745-751 (2015)

17. Sarabia R, Del Ramo J, Varo ' I, D1 'az-Mayans J, \& Torreblanca A Sublethal zinc exposure has a detrimental effect on reproductive performance but not on the cyst hatching success of Artemia partenogenetica. Sci Total Environ 398,48-52 (2008)

18. Go E. C., Pandey A. S. \& MacRae, T. H. Effect of inorganic mercury on the emergence and hatching of the brine shrimp Artemia franciscana. Marine Biology 107, 93-102 (1990).

19. Sarabia, R., Torreblanca, A., Delramo, J. J. \& Diazmayans, J. Effects of low mercury concentration exposure on hatching, growth and survival in Artemia strain La Mata parthenogenesis diploid. Comparative Biochemistry and Physiology Part A: Molecular \& Integrative Physiology 120, 93-97 (1998).

20. Brix, K. V., Gerdes, R. M., Adams, W. J. \& Grosell, M. Effects of copper, cadmium, and zinc on the hatching success of brine shrimp (Artemia franciscana). Arch. Environ. Contam. Toxicol. 51, 580-583 (2006). 
419

420

421

422

423

424

425

426

427

428

429

430

431

432

433

434

435

436

437

438

439

440

441

442

443

444

445

446

447

448

21. Reddy, K. M., Guin, D. \& Manorama. S. V. Selective synthesis of nanosize $\mathrm{TiO}_{2}$ by Hydrothermal route: Characterization, Structure property relation and photochemical applications. Journal of Material Research 19, 2567-95 (2004).

22. Sorgeloos, P. First report on the triggering effect of light on the hatching mechanism of Artemia salina dry cyst. Marine Biology 22, 75-76 (1973).

23. Solis, P. N., Wright, C. W., Anderson, M. M., Gupta, M. P. \& Phillipson, J. D. A Microwell Cytotoxicity Assay using Artemia salina (Brine Shrimp). Planta Medica 59, 250-252 (1993).

24. Sorgloos, P., Van der Wielen, C. R. \&Vitek, J. The use of Artemia nauplii for toxicity tests- A critical analysis. Ecotoxicology and Environmental Safety 2, 249-55 (1978).

25. Ward-Booth, K. \& Reiss, M. Artemia Salina: an easily cultured invertebrate ideally suited for ecological studies. Journal of Biology Education 22, 247-251(1988).

26. MacRae, T. H. \& Pandey, A. S. Effects of metals on early life stages of the brine shrimp, Artemia: A developmental toxicity assay. Arch Environ ContamToxicol 20, 247-252 (1991).

27. Libralato, G., Prato, E., Migliore, L., Cicero, A.M., \& Manfra, L. A review of toxicity testing protocols and endpoints with Artemia spp. Ecol. Indic. 69, 35-49 (2016)

28. Jemec A, Kahru A, Potthoff A, Drobne D, Heinlaan, M; Bohme, S; Geppert, M; Novak, S; Schirmer, K; Rekulapally, R; Singh, S; Aruoja,V; Sihtmae, M; Jganson, K; Kakinen, A \& Kuhnel, D. An interlaboratory comparison of nanosilver characterisation and hazard identification: harmonizing techniques for high quality data. Environmental International 87, 20-32 ( 2016)

29. Nunes, B. S., Carvalho, F. D., Guilhermino, L. M. \& Van Stappen, G. Use of the genus Artemia in ecotoxicity testing. Environmental Pollution 14, 453-462 (2006).

30. Lee, T, H., Chen, Y. M. \& Chou, H. N. Toxicity Assay of Cyanobacterial Strains Using Artemia salina in Comparison with the Mouse Bioassay. Acta Zoologica Taiwanica 10, 1-8 (1999).

31. Rajasree, S. R. R., Kumar, K. G., Abraham, L. S. \& Manoharan, N. Assessment on the toxicity of engineered nanoparticles on the lifestages of marine aquatic invertebrate Artemia salina. International Journal of NanoScience 10, 1153-1159 (2011). 
449

450

451

452

453

454

455

456

457

458

32. Pelka, M., Danzl, C., Distler, W. \& Petschelt, A. A new screening test toxicity testing of dental materials. Journal of Dental Research, 28, 341-345 (2000).

33. Dvorak, P. \&Benova, K. The Investigation of Interactions of Low Doses of Ionizing Radiation and Risk Factors by Means of Artemia salina Biotest. Folia Veterinaria 46, 195-197 (2002).

34. Mayorga, P., Pérez, K. R., Cruz, S. M. \& Cáceres, S. Comparison of Bioassays using the Anostracan Crustaceans Artemia salina and Thamnocephalusplatyurus for Plant Extract Toxicity Screening. RevistaBrasileira de Farmacognosia. Brazilian Journal of Pharmacognosy 20, 897-903 (2010). 
459

460

461

462

463

464

465

466

467

468

469

470

471

472

473

474

475

476

477

478

479

480

481

482

483

484

485

486

487

488

\section{Legends}

Figure 1:Transmission Electron micrograph of nanoparticles suspended in distilled water and high salt solution. Panel on the left represents particles in milliQ water and on right particles in salt water. The particles are $\mathrm{TiO}_{2}$ eNP (A, B); $\mathrm{SiO}_{2}(\mathrm{C}, \mathrm{D}) ; \mathrm{ZnO}(\mathrm{E}, \mathrm{F}) \mathrm{CuO}(\mathrm{G}, \mathrm{H})$ Gold (I, J) and Silver nanoparticles $(\mathrm{K}, \mathrm{L})$. Average size of nanoparticles is mentioned in $\mathrm{nm}$.

Figure 2: Size distributions of nanoparticles in distilled water and salt water. Many nanoparticles show reduced particle size due to dispersion in salt water. $\mathrm{Au}, \mathrm{SiO}_{2}$ (A) and $\mathrm{Ag}$ (B) show reduced particle size in salt water. $\mathrm{TiO}_{2}$ (A), Copper Oxide and Zinc Oxide (B) show higher values when suspended in salt water.

Figure 3: Hatching rate and percent of dead nauplii in the hatching experiment. Silver nanoparticles show the highest toxicity both in terms of hatching and immediate survival of nauplii after hatching. Other nanoparticles show decline in hatching but post-hatching survival is not affected. $\mathrm{SiO}_{2}$ nanoparticles at lower concentration do not affect hatching and survival. * significance $\mathrm{P}<0.05$.

Figure 4: Mortality of nauplii in the standard ARC test. Silver nanoparticles and silver in ionic form (A), show the highest toxicity in concentration dependent manner. All the nanoparticles show concentration dependent mortality, gold $\mathrm{NP}(\mathrm{B}), \mathrm{CuO}(\mathrm{C}), \mathrm{ZnO}(\mathrm{D}) \mathrm{SiO}_{2}(\mathrm{E})$ and $\mathrm{TiO}_{2}(\mathrm{~F})$.

Figure 5: Nauplii of Artemia in standard ARC test stained with DCFDA (green) for ROS and DHE (Red) for superoxide accumulation due to stress. Nauplii exposed to silver $\mathrm{NPs} \mathrm{TiO}_{2}$ and $\mathrm{SiO}_{2} \mathrm{NP}$ show higher staining for both ROS and superoxide at $24 \mathrm{~h}$. [A-D]- control, [E-H]-Silver NP, [I-L]- Gold NP; [M-P]-CuO NP; [Q-T]- ZnO-NP; [U-X]- Titania and [Y-B1]- $\mathrm{SiO}_{2} \mathrm{NP}$

Figure 6: Regression analyses to show correlation between the two sets of results. There is a strong inverse correlation between hatching rate and the mortality in the standard Artemia test (coefficient of correlation -0.748).

Table 1: Size comparison of nanoparticles in milliQ and salt water.

Table 2: Hatching rate of Artemia cysts and immediate mortality of the nauplii.

Table 3: Lethal concentration of nanoparticles for larval toxicity test. 


\section{Figure 1}

TEM of Nanoparticles in distilled and salt water

Transmission Electron micrograph of nanoparticles suspended in distilled water and high salt solution. Panel on the left represents particles in milliQ water and on right particles in salt water. The particles are $\mathrm{TiO}_{2}(\mathrm{~A}, \mathrm{~B}) ; \mathrm{SiO}_{2}(\mathrm{C}, \mathrm{D}) ; \mathrm{ZnO}(\mathrm{E}, \mathrm{F}) \mathrm{CuO}(\mathrm{G}, \mathrm{H}) \mathrm{Gold}(\mathrm{I}, \mathrm{J})$ and Silver (K, $\mathrm{L})$ nanoparticles. The average size of nanoparticles is mentioned in $\mathrm{nm}$. 

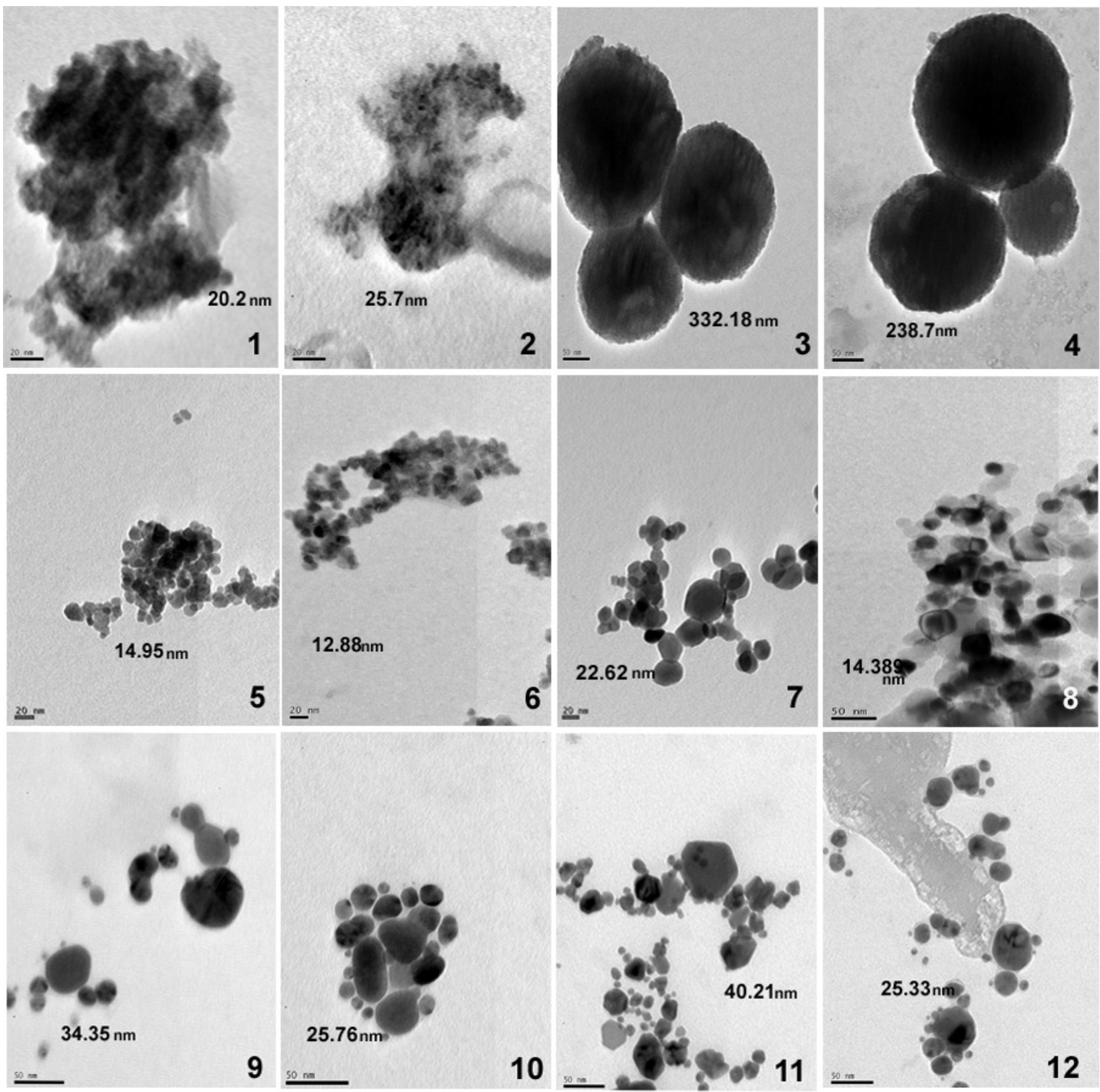
Figure 2

Size of Nanoparticles by DLS

Size distributions of nanoparticles in distilled water and salt water. Many nanoparticles show reduced particle size due to dispersion in salt water. $\mathrm{Au}, \mathrm{SiO}_{2}(\mathrm{~A})$ and $\mathrm{Ag}(\mathrm{B})$ show reduced particle size in salt water. $\mathrm{TiO}_{2}(\mathrm{~A})$, Copper Oxide and Zinc Oxide (B) show higher values when suspended in salt water.

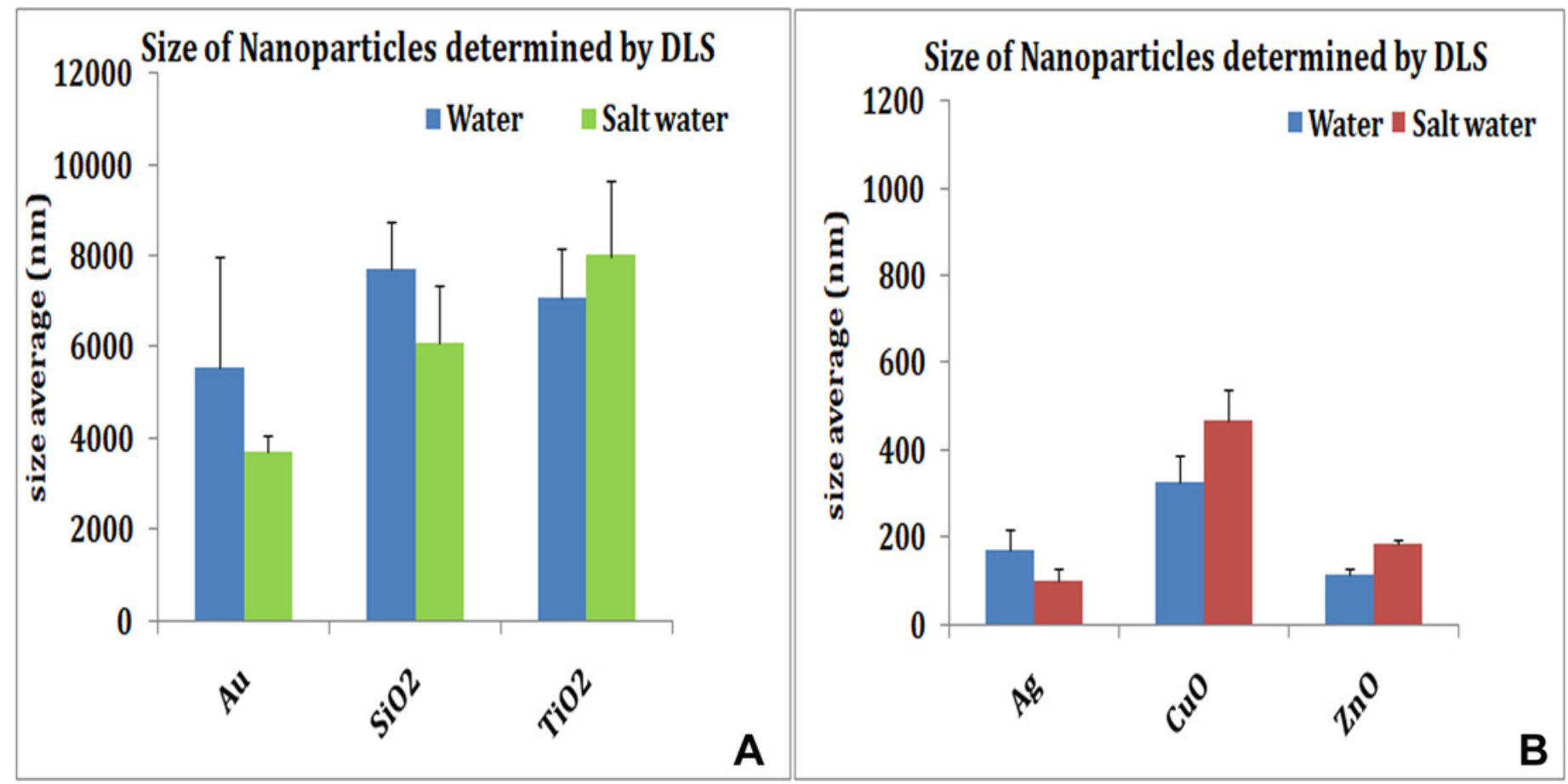


Figure 3

Hatching rate and mortality

Hatching rate and percent of dead nauplii in the hatching experiment. Silver nanoparticles show the highest toxicity both in terms of hatching and immediate survival of nauplii after hatching. Other nanoparticles show decline in hatching but post-hatching survival is not affected. $\mathrm{SiO}_{2}$ nanoparticles at lower concentration do not affect hatching and survival. * significance $\mathrm{P}<0.05$.

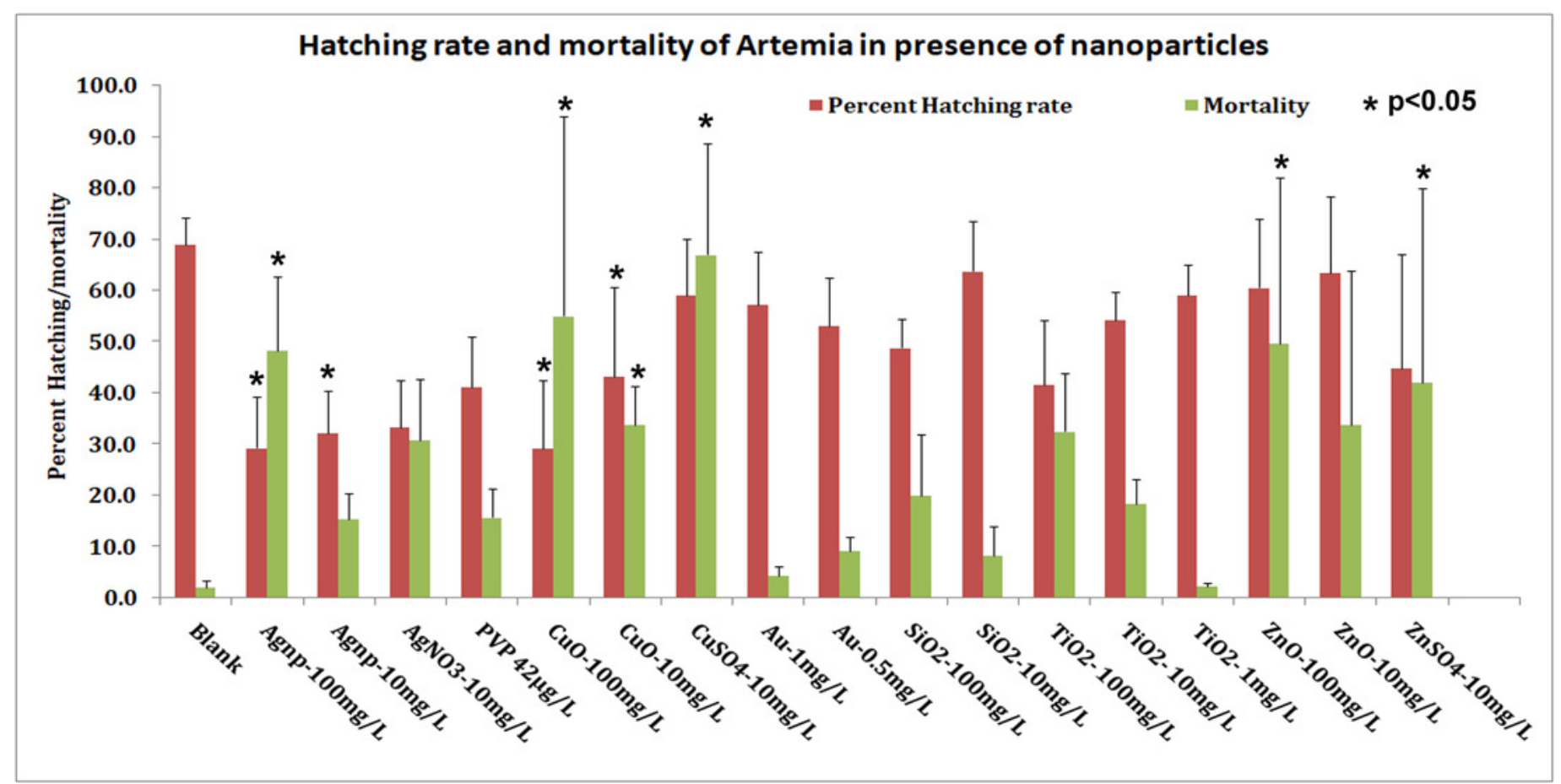


Figure 4

Mortality of nauplii in standard ARC test

Mortality of nauplii in the standard ARC test. Silver nanoparticles and silver in ionic form (A), show the highest toxicity in a concentration-dependent manner. All the nanoparticles show concentration-dependent mortality, gold NP (B), $\mathrm{CuO}(\mathrm{C}), \mathrm{ZnO}(\mathrm{D}) \mathrm{SiO}_{2}(\mathrm{E})$ and $\mathrm{TiO}_{2}(\mathrm{~F})$.

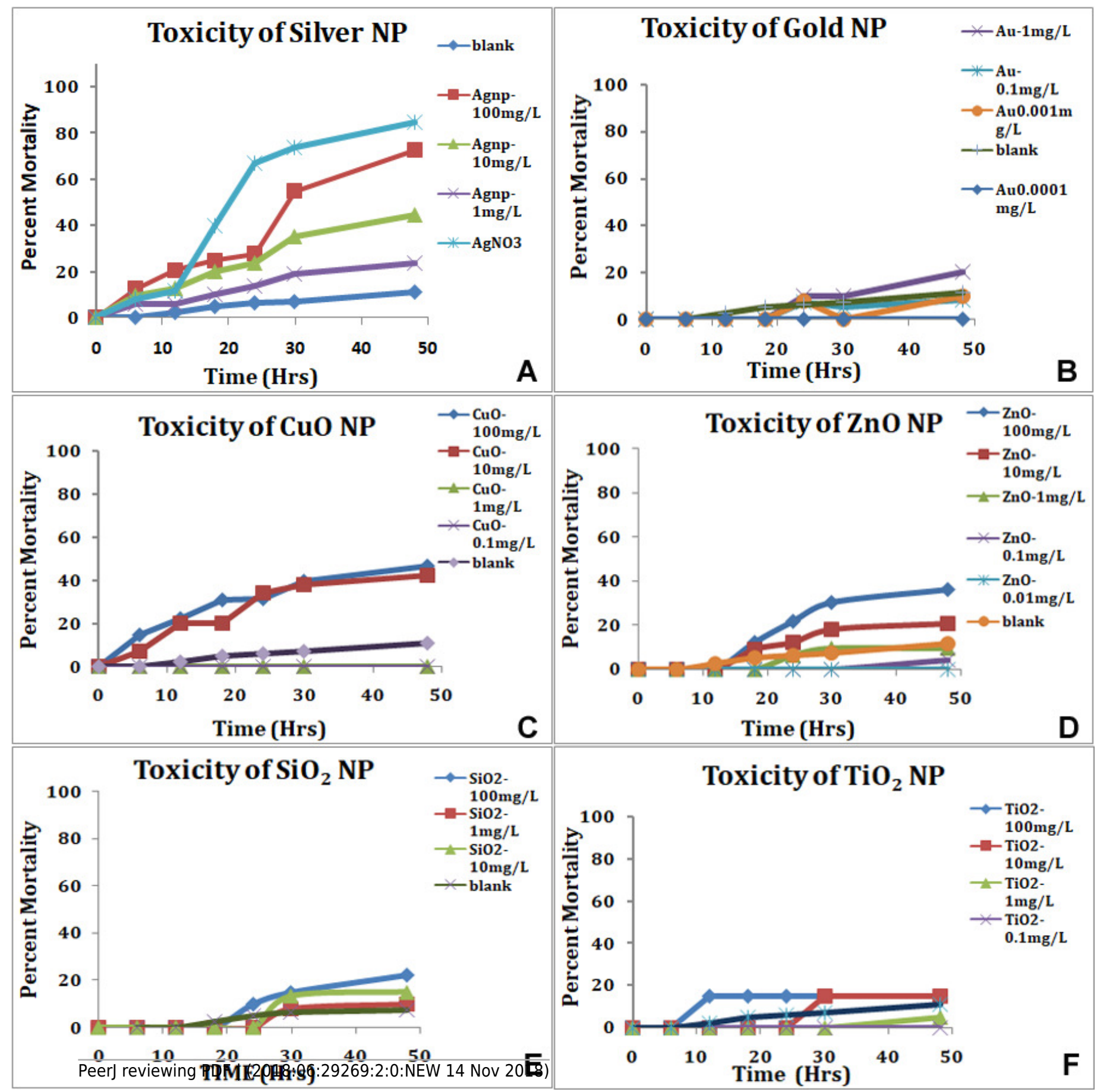




\section{Figure 5}

ROS staining of dead nauplii

Nauplii of Artemia in standard ARC test stained with DCFDA (green) for ROS and DHE (Red) for superoxide accumulation due to stress. Nauplii exposed to silver $\mathrm{NPs}, \mathrm{TiO}_{2}$, and $\mathrm{SiO}_{2} \mathrm{NP}$ show higher staining for both ROS and superoxide at $24 \mathrm{~h}$. [A-D]- control, [E-H]-Silver NP, [IL]- Gold NP; [M-P]-CuO NP; [Q-T]- ZnO -NP; [U-X]- Titania and [Y-B1]- $\mathrm{SiO}_{2} \mathrm{NP}$. 


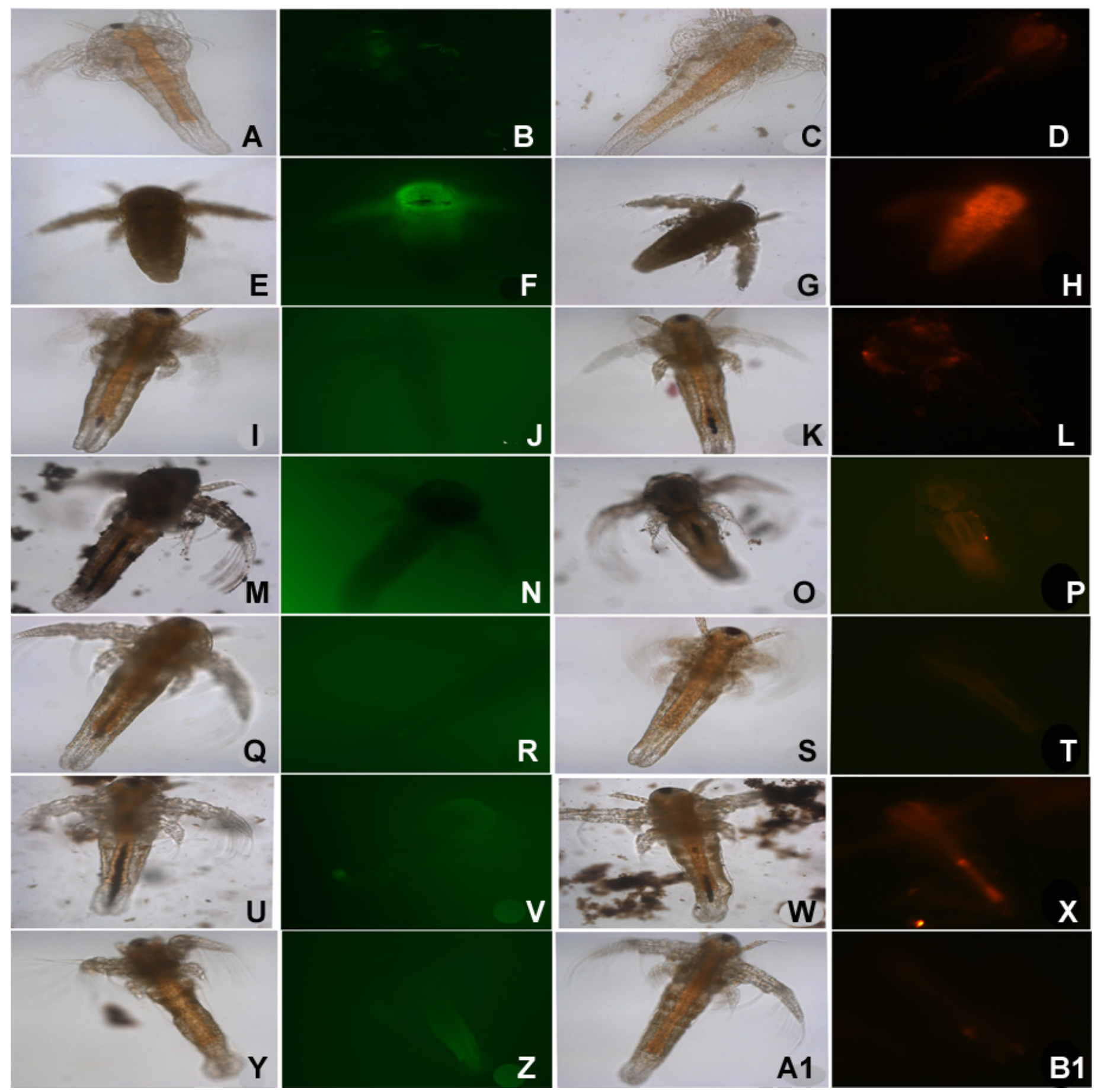


Figure 6

Correlation graph

Regression analyses to show the correlation between the two sets of results. There is a strong inverse correlation between the hatching rate and the mortality in the standard Artemia test (coefficient of correlation -0.748).

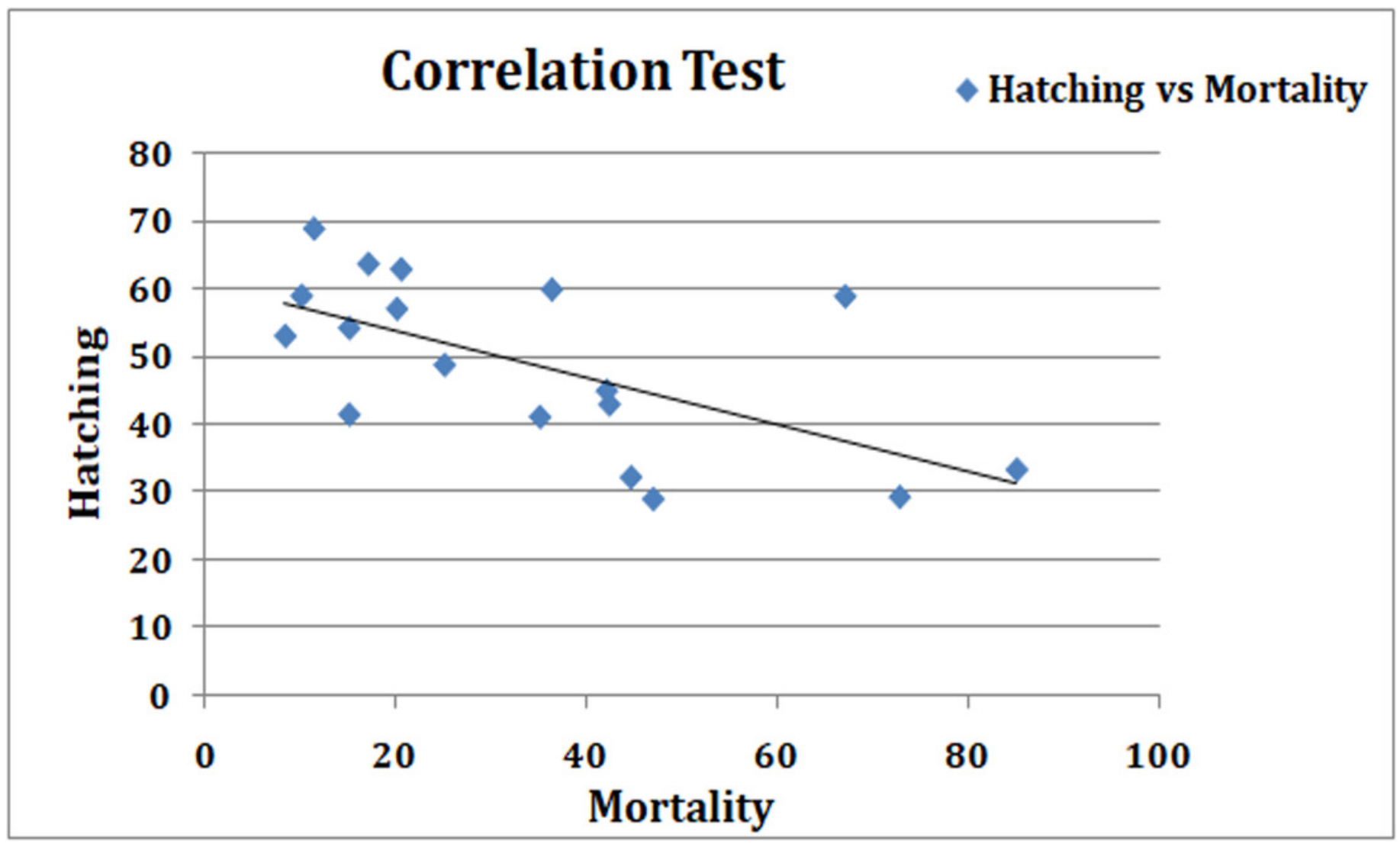




\section{Table 1 (on next page)}

Size comparison

Size comparison of the nanoparticles in milliQ water and salt water 
1 Table 1: Size comparison of nanoparticles in milliQ water and salt water

\begin{tabular}{|c|c|c|c|c|c|c|c|c|c|c|}
\hline \multirow[t]{3}{*}{$N P$} & \multicolumn{4}{|c|}{ TEM } & \multirow{3}{*}{$\begin{array}{c}\mathrm{P} \\
\text { value }\end{array}$} & \multicolumn{4}{|c|}{ DLS } & \multirow[t]{3}{*}{$P$ value } \\
\hline & \multicolumn{2}{|c|}{ MilliQ } & \multicolumn{2}{|c|}{ Salt water } & & \multicolumn{2}{|c|}{ MilliQ } & \multicolumn{2}{|c|}{ Salt water } & \\
\hline & mean & SEM & mean & SEM & & mean & SEM & mean & SEM & \\
\hline $\begin{array}{l}\mathrm{SiO} \\
2\end{array}$ & $\begin{array}{l}332.1 \\
8\end{array}$ & $\begin{array}{l}98.23 \\
5\end{array}$ & 238.7 & 41.10 & 0.3814 & 7703 & $\begin{array}{l}1041.54 \\
8\end{array}$ & 6095 & $\begin{array}{l}1248.25 \\
1\end{array}$ & 0.3786 \\
\hline $\begin{array}{l}\mathrm{TiO} \\
2\end{array}$ & 20.2 & $\begin{array}{l}6.438 \\
8\end{array}$ & 10.82 & 0.132 & 0.1474 & 7081 & $\begin{array}{l}1094.14 \\
8\end{array}$ & 8008.9 & $\begin{array}{l}1643.14 \\
7\end{array}$ & 0.6628 \\
\hline $\begin{array}{l}\mathrm{Zn} \\
\mathrm{O}\end{array}$ & $\begin{array}{l}14.95 \\
4\end{array}$ & 2.9 & $\begin{array}{l}12.88 \\
8\end{array}$ & 11.55 & 0.8625 & 117.1 & 12.869 & 184.8 & 8.488 & 0.0118 \\
\hline $\begin{array}{l}\mathrm{Cu} \\
\mathrm{O}\end{array}$ & $\begin{array}{l}22.62 \\
8\end{array}$ & 5.77 & $\begin{array}{l}14.38 \\
9\end{array}$ & 1.337 & 0.1663 & 328.95 & 58.76 & 467.66 & 72.266 & 0.2107 \\
\hline $\mathrm{Au}$ & 34.35 & $\begin{array}{l}13.23 \\
3\end{array}$ & 25.76 & 3.463 & 0.5310 & $\begin{array}{l}5542.66 \\
7\end{array}$ & $\begin{array}{l}2457.83 \\
8\end{array}$ & $\begin{array}{l}3712.66 \\
7\end{array}$ & $\begin{array}{l}341.176 \\
4\end{array}$ & 0.5017 \\
\hline $\mathrm{Ag}$ & 40.21 & 12.19 & 25.33 & $\begin{array}{l}12.20 \\
9\end{array}$ & 0.3898 & $\begin{array}{l}169.433 \\
3\end{array}$ & 50.99 & 100.725 & 26.525 & 0.2979 \\
\hline
\end{tabular}

2

$3 \mathrm{~N}=75$ for TEM

$4 \quad \mathrm{~N}=3$ for DLS 


\section{Table 2 (on next page)}

Hatching rate

Hatching rate of Artemia cysts and immediate mortality of the nauplii. 
1 Table 2: Hatching rate of Artemia cysts and immediate mortality of the nauplii.

2

\begin{tabular}{|c|c|c|c|c|c|c|c|}
\hline Hatching & $\begin{array}{c}\text { Concentration } \\
\text { of eNP }\end{array}$ & $\begin{array}{c}\text { Percent } \\
\text { Hatching } \\
\text { rate }\end{array}$ & SEM & $\begin{array}{c}\mathrm{p} \\
\text { value }\end{array}$ & $\begin{array}{l}\text { Immediate } \\
\text { Mortality } \\
\text { of } \\
\text { hatchlings }\end{array}$ & SEM & $\begin{array}{c}\mathrm{p} \\
\text { value }\end{array}$ \\
\hline Blank & & 74.6 & 5.18 & & 2.03 & 1.3 & \\
\hline AgNP & $100 \mathrm{mg} / \mathrm{L}$ & 29.3 & 9.978 & 0.013 & 48.31 & 14.51 & 0.010 \\
\hline AgNP & $10 \mathrm{mg} / \mathrm{L}$ & 32.2 & 8.24 & 0.010 & 15.35 & 5.0 & 0.033 \\
\hline AgNO3 & $10 \mathrm{mg} / \mathrm{L}$ & 33.4 & 9.19 & 0.019 & 30.71 & 12.1 & 0.043 \\
\hline PVP & $42 \mu \mathrm{g} / \mathrm{L}$ & 41.1 & 9.95 & 0.079 & 15.71 & 5.62 & 0.046 \\
\hline AuNP & $1 \mathrm{mg} / \mathrm{L}$ & 57.1 & 10.41 & 0.622 & 4.31 & 1.83 & 0.46 \\
\hline AuNP & $0.5 \mathrm{mg} / \mathrm{L}$ & 53.1 & 9.39 & 0.378 & 9.08 & 2.8 & 0.069 \\
\hline $\mathrm{SiO}_{2} \mathrm{NP}$ & $100 \mathrm{mg} / \mathrm{L}$ & 48.9 & 5.60 & 0.390 & 20.04 & 11.9 & 0.176 \\
\hline $\mathrm{SiO}_{2} \mathrm{NP}$ & $10 \mathrm{mg} / \mathrm{L}$ & 63.8 & 9.65 & 0.943 & 8.18 & 5.8 & 0.365 \\
\hline $\mathrm{TiO}_{2} \mathrm{NP}$ & $100 \mathrm{mg} / \mathrm{L}$ & 41.51 & 12.68 & 0.147 & 32.5 & 11.4 & 0.028 \\
\hline $\mathrm{TiO}_{2} \mathrm{NP}$ & $10 \mathrm{mg} / \mathrm{L}$ & 54.3 & 5.48 & 0.275 & 18.41 & 4.8 & 0.159 \\
\hline $\mathrm{TiO}_{2} \mathrm{NP}$ & $1 \mathrm{mg} / \mathrm{L}$ & 59.07 & 6.01 & 0.631 & 2.20 & 0.7 & 0.062 \\
\hline CuONP & $100 \mathrm{mg} / \mathrm{L}$ & 29.14 & 13.25 & $\begin{array}{c}< \\
0.0001 \\
\end{array}$ & 55.00 & 39.02 & 0.008 \\
\hline $\mathrm{CuONP}$ & $10 \mathrm{mg} / \mathrm{L}$ & 43.24 & 17.33 & $\begin{array}{c}< \\
0.0001 \\
\end{array}$ & 33.82 & 7.41 & 0.054 \\
\hline $\mathrm{CuSO}_{4}$ & $10 \mathrm{mg} / \mathrm{L}$ & 59.06 & 11.07 & 0.0078 & 47.00 & 21.74 & $\begin{array}{c}< \\
0.0001 \\
\end{array}$ \\
\hline ZnONP & $100 \mathrm{mg} / \mathrm{L}$ & 60.53 & 13.36 & $\begin{array}{c}< \\
0.0001 \\
\end{array}$ & 49.60 & 32.5 & 0.002 \\
\hline $\mathrm{ZnONP}$ & $10 \mathrm{mg} / \mathrm{L}$ & 63.38 & 14.97 & $\begin{array}{c}< \\
0.0001\end{array}$ & 33.75 & 30.14 & 0.012 \\
\hline $\mathrm{ZnSO}_{4}$ & $10 \mathrm{mg} / \mathrm{L}$ & 44.72 & 22.27 & $\begin{array}{c}< \\
0.0002\end{array}$ & 42.00 & 37.97 & 0.014 \\
\hline
\end{tabular}

3

4 


\section{Table 3(on next page)}

Lethal concentration of nanoparticles for larval toxicity test.

Lethal concentration of nanoparticles for the larval toxicity test. 
Table 3:Lethal concentration of nanoparticles for larval toxicity test.

\begin{tabular}{|c|c|c|}
\hline Nanoparticle & 24 hour LC50 & $48 \mathrm{~h}$ hour LC50 \\
\hline $\mathrm{Ag}$ & $10.12 \mathrm{mg} / \mathrm{L}$ & \\
\hline $\mathrm{AgNO}_{3}$ & $8.190 \mathrm{mg} / \mathrm{L}$ & \\
\hline $\mathrm{Au}$ & & $7.54 \mathrm{mg} / \mathrm{L}$ \\
\hline $\mathrm{SiO} 2$ & & $23.59 \mathrm{mg} / \mathrm{L}$ \\
\hline $\mathrm{TiO} 2$ & & $18.94 \mathrm{mg} / \mathrm{L}$ \\
\hline $\mathrm{CuO}$ & & $20.92 \mathrm{mg} / \mathrm{L}$ \\
\hline $\mathrm{CuSO} 4$ & & $13.45 \mathrm{mg} / \mathrm{L}$ \\
\hline $\mathrm{ZnO}$ & & $259.34 \mathrm{mg} / \mathrm{L}$ \\
\hline $\mathrm{ZnSO} 4$ & & $0.796 \mathrm{mg} / \mathrm{L}$ \\
\hline & & \\
\hline
\end{tabular}

